\title{
BIFURCATIONS ON THE ROAD: CONFLICTING INTENTIONS AND DEMONSTRATIVE REFERENCE ${ }^{1}$
}

\author{
Matheus Valente \\ https:/ / orcid.org/0000-0001-6380-2623 \\ University of Barcelona \\ Department of Philosophy \\ Barcelona \\ Spain \\ matheusvalenteleite@gmail.com
}

\author{
Article info \\ CDD: 401 \\ Keywords \\ Reference \\ Conflicting Intentions \\ Demonstratives \\ Indexicals \\ Content
}

Received: 17.08.2020; Revised: 26.08.2020; Accepted: 26.08.2020

https://doi.org/10.1590/0100-6045.2020.V43N4.ML

\begin{abstract}
This is a critical notice of Mario Gómez-Torrente's novel account of demonstrative reference presented in chapter 2 of the recently published book Roads to Reference. After presenting the main tenets of his view (including the existence of a multitude of cases where demonstrative reference is
\end{abstract}

${ }^{1}$ I thank Mario Gómez-Torrente for commentaries to an early draft of this paper, Martín Abreu Zavaleta for organizing an online workshop on Mario's book, Tamires Dal Magro for her suggestions, and the editors and reviewers of Manuscrito. Work on this paper has received funding from the European Union's Horizon 2020 Research and Innovation programme under Grant Agreement no. 675415. Work on this paper has also received financial and logistical support from the CNRS, the Institut Jean Nicod, and the Collège de France. 
indeterminate), I go on to critically examine a couple of its features. In section 2, I assess Gómez-Torrente's assumption that demonstrative thought based on perception is less likely to succumb to indeterminacy than the others. I show that this aspect of his view invites unwelcome consequences regarding the transparency of thought. I do however suggest that this problem could be overcome by individuating perceptual intentions dynamically. In section 3, I express a distinct worry regarding a case, introduced en passant by Gómez-Torrente, that involves successful demonstrative reference regardless of its utterer's conflicting intentions, a result that seems to contradict his general theory. Instead of conceiving the case as exceptional, I use it to motivate the necessity of distinguishing between a subject's referential intentions and a subject's merely collateral beliefs about the target of his utterance.

\section{CONFLICTING INTENTIONS}

It's Friday night: as I'm taking a generous sip of an ice-cold glass of beer, I notice its distinctive smell of fresh barley and delightfully exclaim: 'This is heaven on earth!'. However, the beer I'm drinking is odorless, and the smell of barley is actually coming from my neighbor's oven (like so many of us, he's recently got into bread-baking during the Covid-19 confinement). My demonstrative utterance thus seems "conflicted" - it is at once directed at the beer I'm tasting, and at the bread I'm smelling. What does it refer to - if anything?

For cases similar to these, Siegel (2002, p. 11) claims "[t]here are three options: it refers to one of the candidate objects but not the other; it fails to refer altogether; or it refers to both objects." One of the many contributions that Gómez-Torrente's (2019, chapter 2) gives to this debate is the realization that there actually is a fourth option: the demonstrative neither refer nor fails to refer, it is referentially 
indeterminate. Albeit novel, this proposal seems to fit all the bills it is supposed to fit, including being able to ground a reference-fixing theory of demonstratives that is, as Speaks (2017, p. 714) argues it should be, both adequate and internalizable (Gómez-Torrente, pp. 38-39). The heart of Gómez-Torrente's proposal is that we need not find exception-proof conditions for demonstrative reference; instead, he argues, we can rest content with an informative set of sufficient (but not necessary) conditions allowing us to assess some cases as successful, others as determinate failures, but also many others as referentially indeterminate.

Gómez-Torrente's novel proposal makes distinctions where previously there was none. Much good philosophy is about drawing insightful distinctions, and his account of demonstrative reference surely achieves that feat. Let us give it a closer look, focusing on cases of conflicting intentions such as the one presented above.

I started by pointing out that Gómez-Torrente shows that there are four where people thought there were three. Actually, if we want to be more precise, this is not quite true: Gómez-Torrente considers only three, not four, types of verdict in his discussion. Sometimes a use of a demonstrative refers, sometimes it fails to refer (and is thus empty), but sometimes it neither refers nor fails to refer. Cases of conflicting intentions can then be sorted out in three boxes: Refers, Fails or Neither. ${ }^{2}$

Take, again, my story about the beer and the bread. Classifying it under Refers (i.e. saying that 'this' refers either

\footnotetext{
${ }^{2}$ What about Both, i.e. the proposal favored by Siegel according to which a demonstrative might have multiple referents? GómezTorrente fails to consider it. If you're curious about the "multiple referents" views, take a look at Ricardo Mena's insightful contribution on this very volume (which does justice to the view to a much fuller extent than I could hope to).
} 
to the beer or to the bread) seems implausible. There just seems to be no way to privilege the beer over the bread (or vice-versa) as the referent of my utterance - my demonstrative seems just as directed at one as at the other. But classifying it under Fails is, according to GómezTorrente, equally problematic: a competent speaker, apprised of all the relevant facts, "will not risk with any confidence a judgment that my 'this', in virtue of the conflict of my intentions, was definitely not referring to anything" ( $p$. 43). The ordinary conventions regulating demonstrative reference seem to be just as silent about whether I successfully refer, than about whether I don't refer to anything. This is basically why, according to the view presented on Roads to Reference, my case should be subsumed under Neither: it is referentially indeterminate.

In section 2 below, I express a few worries about GómezTorrente's assumption that demonstrative thought based on perceptual referential intentions grounds are less likely to succumb to indeterminacy than the others. More specifically, I show that this aspect of his view might invite unwelcome consequences regarding the transparency of thought. I do however finish this section by suggesting how this problem could be overcome. In section 3, I express a distinct worry regarding an interesting case that Gómez-Torrente discusses (perhaps too hastily) in a footnote of his book. I use it to motivate the necessity of distinguishing between a subject's referential intentions and a subject's merely collateral beliefs about the target of his utterance.

\section{Privileged Perceptual InTENTIONS}

I have said that Gómez-Torrente would classify my story under Neither but I left a part of the explanation out. He assumes, and I concur, that there are three main types of 
referential intentions in play when speakers utter demonstratives: perceptual, memorial and descriptive.

A perceptual referential intention involves a perceptual (e.g. visual, tactual, olfactory) link to the thing one intends to refer to. A memorial intention involves a mnemonic (as in an episode of remembering) link to a thing one has previously been in perceptual contact with. Finally, a descriptive intention involves a purely qualitative link to the referent (the referent is latched onto by the fact that it is supposed to uniquely possess a certain qualitative property). Cases of conflicting intentions can involve any combination of these three types of intentions, e.g. Perceptual/Perceptual, Perceptual/Memorial, Perceptual/Descriptive, Memorial/

Memorial, Memorial/Descriptive, Descriptive/Descriptive. Whether a case falls into the Refers, Fails or Neither box crucially depends on which combination of referential intentions is in play.

Let us focus on cases where there are two conflicting intentions that successfully latch onto distinct objects (and ignore cases of hallucinations, of quasi-memories, of descriptions which are not uniquely satisfied etc.). If the conflict does not involve a perceptual intention, then the verdict is always Neither. This is so because, on GómezTorrente's view, memorial and descriptive referential intentions are very fragile - they only allow a referent to a demonstrative use when they are successful and unaccompanied by conflicting intentions of any kind. ${ }^{3}$ Things are very different with respect to perceptual intentions. These are quite robust: only other perceptual intentions might cause problems to them. In other words, as

\footnotetext{
3 Alternatively, they only determinately fail to refer when (i) they fail to latch onto a referent and (ii) there is no accompanying conflicting intention. On Gómez-Torrente's view, no conflicting intentions case is ever classified as Fails.
} 
long as one's use of a demonstrative is based on a successful perceptual referential intention, it will refer to the object perceptually picked out unless there is another conflicting perceptual referential intention (independently of whether there are other conflicting memorial or descriptive intentions in play). This is precisely what happens in the beer and bread case: I have two conflicting perceptual referential intentions (one based on taste, another on smell), thus, according to Gómez-Torrente, the case should be classified as Neither.

Perceptual referential intentions are hard to beat, but why? Let me express a few worries about that idea. First, it seems worrisome to Gómez-Torrente's view how easily a case can be transformed from Perceptual/Perceptual (and thus classifiable as Neither) to a Perceptual/Memorial or Perceptual/Descriptive (and thus classifiable as Refers). Take the beer and bread story. Since my utterance of 'this' is based on two conflicting (taste and smell) perceptual intentions, the case is one of Neither: I neither refer nor fail to refer to anything. However, it doesn't require more than pinching my nose (and thus blocking the smell) for a successive use of 'this' to determinately refer to the beer the remaining taste-perceptual link would beat the smellmemorial one. Conversely, it doesn't require more than spitting the beer (assuming this clears my palate) for a new use of 'this' to refer to the bread - smell-perceptual links beat taste-memorial ones.

This argument can be made even more dramatic in cases where vision and tact are at issue, such as in the tree hugger example presented by Gómez-Torrente (p. 42). Assume I'm seeing and hugging two trees thinking it's only one. If I close my eyes and say 'this tree', then I refer to the tree I'm touching (even though I also intend to refer to the tree I remember seeing just a moment ago). If I open my eyes, but stop hugging the tree, my new use of 'this tree' will then refer 
to the tree I'm seeing (even though I also intend to refer to the tree I remember touching just a moment ago).

This is weird, but is it a real problem? Maybe it's just very easy for demonstrative reference to oscillate between success and indeterminacy - so what? Well, I'm worried this might invite more serious issues with respect to diachronic cases. Think of this very ordinary case of perceptual tracking. There are many bees flying in your visual field. You focus your eyes on a specific male bee and start following it as it slowly paces around; you think 'this is a striped bee'. Since the only referential intention at this stage is a perceptual visual link to one bee, you successfully refer to it. But then the bee picks us some speed and, as it crosses the path of another one, you unknowingly start following the other female bee. Taking it to be the same as before, you think 'this is a female bee'. Now you're in a Perceptual(visual)/Memorial("the same bee as I was tracking before") case. Still, perception always trumps memory, and you successfully refer to the female bee. You then make an existential generalization on the basis of your two thoughts: 'there exists a female striped bee'. This reasoning does not seem to be invalid or logically blameworthy - still, if we follow Gómez-Torrente's view on demonstrative reference-fixing, it will be "formalizable" as an existential generalization on the basis of premises about distinct referents. You have thus committed a logical mistake (more specifically, you've made an existential generalization of the form $\exists x(F x \& G x)$ on the basis of premises whose form is $a$ is $F$ and $b$ is $G$ ).

This kind of issue might be beside the point with respect to Gómez-Torrente's main objectives, but it strikes me as a fair point to raise, and an unwelcome (and unspoken) consequence of the asymmetry entailed by privileging perceptual referential intentions. Considerations not unlike those made authors such as Recanati (2016, chapter 3, 2019) suggest that cases of confusion must lead to reference failure 
or, in the terminology we've been employing, to classify all or most cases of conflicting intentions in the Fails box. ${ }^{4}$ Recanati's rationale is that, if one of the premises in the inference fails to refer (instead of referring to a second object), then the subject cannot be accused of having traded on the identity of premises with distinct referents - the subject has merely failed to see that one of the premises did not refer to anything (still a mistake, but not a "logical" one).

Maybe this is too abstract. I'll finish with a more vivid case which makes a related point - this will also be an opportunity to invite Gómez-Torrente to discuss a set of cases which are left out of the book: spatial indexicals. ${ }^{5}$

I'm standing in the center of the Azteca Stadium in Mexico City and I utter "bere two world cup finals have begun'. 'Here' is more or less a demonstrative, but it doesn't really matter - my only referential intention at this stage is to refer to the place I'm standing at, so I seem to succeed. I then run all the way to (what I take to be) the other extreme of the field and attempt to point to the center of the field and re-express the same thought I had just expressed: 'as I've just said, there is where two world cup finals have begun'. Unfortunately, I'm a bit breathless from running, so I actually mistake the center of the Azteca stadium with one of its corners (you can add in a bit of myopia too if you want).

\footnotetext{
${ }^{4}$ Recanati (2016, chapter 3-5) is mostly concerned with cases of perceptual tracking, where successive episodes of demonstrative reference within the episode presuppose co-reference with the previous ones. Recanati's presuppositions of co-reference can, I take it, be framed as memorial referential intentions in GómezTorrente's terminology.

${ }^{5}$ Similar considerations could be raised with respect to temporal indexicals, if only we assumed that 'today' refers to the current day by means of a perceptual (or perceptual enough) referential intention.
} 
Thus, when I utter 'there' I both intend to refer to the place I'm looking at (the corner) and to the place I was just at (the center). This is, I take it, a Perceptual/Memorial case. Since perception trumps memory, I end up successfully referring to the corner. In conclusion, in attempting to re-express the same thought I had just expressed, I actually end up referring to a completely distinct thing. Re-expressing a thought should be as easy as thinking the same thing twice - still, I seem to fail.

Why is that a problem? Well, if we assume that thoughts whose referents are distinct cannot be the same, then, in the story I've just told, I express a distinct thought in an attempt to re-express one. This means that we can be confused about the type-identity of the thoughts we express, and thus, that the contents of our utterances (the thoughts they express) are not transparent to us, i.e. their identity or distinctness is not apriori assessable. This opens the way for the possibility that, not only the identity of the things we refer to (which everybody agrees is not apriori assessable), but also the sameness and distinctness of our own thoughts themselves is opaque to us. Gómez-Torrente's privileging of perceptual referential intentions thus seems to have a strong consequence that is not discussed in his (otherwise so complete) book: according to his view, demonstrative thought is not transparent.

How could Gómez-Torrente avoid that problem? There might be more than one way, but here's my preferred one. Not much has been said about how to individuate a perceptual intention. Crucially, we have assumed they are individuated by particularly fine-grained time-slices, "the intention to refer to the object I'm perceiving right now at this very moment'. However, given that perceptual episodes are spread out in time, we could opt to individuate them dynamically, "the intention to refer to the object I'm perceiving during the entirety of this perceptual episode". If this 
proposal is tenable (and I see no reason why it is not), we could then argue that, in most of the stories we've analyzed above, the two demonstrative utterances are done within the context of the same dynamic perceptual episode where the univocity of the target object is presupposed. The perceptual intentions behind my two utterances are then not independent; they can be described as involving one and the same perceptual episode. When I think about the "second" bee, for instance, my referential intention is to refer to the bee that I've been tracking during the entire perceptual episode I'm undergoing, and not only to the bee that I'm tracking at that very moment. This guarantees that I will not successfully refer to the "second" bee - the case would fall under either the Fails or the Neither box, depending on how one fleshes out some further details ${ }^{6}$. In any case, this would be enough to pave a way for maintaining the transparency of thought within Gómez-Torrente's theory.

\section{REFERENTIAL INTENTIONS VERSUS COLLATERAL BELIEFS}

Above I worried about perceptual intentions trumping all others, but I also worry about how descriptive and memorial intentions never trump any other. Indeed, I don't seem to be alone in this worry: Gómez-Torrente admits, albeit only in a footnote (fn. 25, p. 54), that there are cases of conflicting descriptive intentions where we might need to accept that reference is successful. The telling case (p. 36) involves a

${ }^{6}$ There is room for discussion, but, when the same dynamic perceptual episode involves the tracking of distinct objects (two bees, the center and the corner of the stadium), it seems that the subject's perceptual intention determinately fails to refer. The case would then fall under Fails. 
subject who, after thinking about several possible courses of action, says 'That's what I have to do!' both with the intention of referring to the event of donating money to his friend John's organization, and of referring to the event of donating money to the most effective charity NGO in town. As it happens, his friend John's organization is actually a fraudulent scheme, so the subject mistakenly believes that the two descriptive intentions point to the same action when they do not. Still, Gómez-Torrente argues, and I concur, that the demonstrative 'that' seems to successfully refer to his donating money to his friend's organization (and not to the NGO that in fact is the most effective in town).

Gómez-Torrente tentative explanation of that case is that only one of the two descriptive intentions represents its target referent by means of a description that allows the subject "to go about identifying the object" (fn. 25, p. 54), and that these types of intentions trump the others, even if one's in a Descriptive/Descriptive case. ${ }^{7}$ Gómez-Torrente's rationale seems to be: if all $\mathrm{I}$ know is that I need to donate money to the most effective NGO in town, I won't be in a position to do that before doing some research about which NGO that is; if, on the other hand, I know that it is my friend John's organization, I can readily call him and wire him the money.

I think I see what Gómez-Torrente is trying to get at, but I suspect this kind of reasoning falls short of achieving what we need. It is just not clear how to assess which descriptions allow us to identify a thing and, even if one somehow makes that notion more precise, it seems it won't be of much help in accounting for demonstrative reference in cases such as the one above. Imagine, for example, that the subject in the

\footnotetext{
${ }^{7}$ It's not clear if the same goes for memorial intentions. What would it mean for a thing to be represented in a memorial intention by a description that allows one to identify it?
} 
story knows of a website that includes a database of the most effective NGOs in town but has no idea of how to contact his friend John, or even what his organization was called. If that was the case, the intention that represents the event by a description that helps prompt identification of the NGO would have been the former, unlike in (what I take to be) Gómez-Torrente's description of the story. Regardless of that, I think demonstrative reference would not change: the subject would still have referred to the event of donating to his friend John's organization.

I don't have an alternative explanation of why the subject is referring to (the event of donating to) John's NGO, but I think the paragraph above suggests it doesn't have to do with which referential intention is more likely to help the subject "identify the referent" (however vague that notion may be). I do, however, have a hunch. When I act this story in the theater of my mind, I imagine that the subject has already decided that he must donate money to the most effective NGO in town, but he doesn't know which one that is. When he comes to (wrongly) believe that it is his friend John's organization, an eureka moment occurs: 'that's what I have to do!'. This means that, at the time of the demonstrative utterance, the fact that John's organization is the most effective in town is much more salient than any other. Actually, I want to say something even stronger: I think that the only intention he has at the moment is that of referring to donating to his friend John's organization, and that his taking that organization to be the most effective in town is only a collateral belief of his, not a part of his referential intentions at that time. ${ }^{8}$

8 Perhaps Gómez-Torrente would deny my description of the story and insist that the subject actually gives equal weight to the two ways of describing the event. However, under this assumption, I 
In more general terms, I think we should be able to distinguish between a subject's referential intentions and the collateral beliefs that this subject holds about the target of his intentions. Not being able to do that will not only cause problems with respect to the story above, but with virtually any case of demonstrative reference with descriptive intentions. We normally have a multitude of beliefs about the things we try to refer to, and many of those are bound to be misfire even in the most ordinary cases. The subject in the story, for example, not only mistakenly believes John's organization is the most effective in town, he also mistakenly believes (let's assume) it is located on Plaza del Zócalo, when in fact another NGO is located in that square. But that mistaken belief, I think Gómez-Torrente would agree, does not seem relevant to his referential intentions. It's just something he (as a matter of fact) believes about the target of his utterance. If we can distinguish between collateral beliefs and referential intentions in that case, we should be capable of doing it in a general and systematic fashion as well.

Although this is only a hunch, I think developing that distinction would be highly beneficial to Gómez-Torrente's theory of demonstrative reference, for it would provide a way to account for the NGO case without having to postulate the existence of special cases where some descriptive referential intentions are qualitatively distinct, and thus trump the others. Under my tentative explanation, the subject in that story has one and only one referential intention at the time of the utterance, i.e. to refer to the event of donating to his friend John's organization. But then, this is not a case of conflicting intentions - i.e. there is no bifurcation on the road of demonstrative reference. It thus

feel that my intuition of successful reference starts to dissipate, and I'd be more prone to classify the case as either Neither or Fails. 
shouldn't surprise anybody that he successfully refers, which is what we wanted from the start.

\section{REFERENCES}

Gomez-Torrente, Mario (2019). Roads to Reference. An Essay on Reference Fixing in Natural Language. Oxford, United Kingdom: Oxford University Press.

Siegel, Susanna (2002). 'The role of perception in demonstrative reference'. Philosophers' Imprint 2:1-21.

Recanati, François (2016). Mental Files in Flux. Oxford University Press.

Recanati, François (forthcoming). 'Transparent Coreference'. Topoi. 